\title{
pÿ What are you taking away with you? : Closing radio counselling encounters by reviewing progress
}

\section{Thell, Natalyia}

2018-06

pÿThell , N \& Peräkylä , A 2018 , ' What are you taking away with you? : Closing radio counselling encounters by reviewing progress ', Discourse Studies, vol. 20 , no. 3 , pp. 377-396 . https://doi.org/10.1177/1461445618754420

http://hdl.handle.net/10138/235572

https://doi.org/10.1177/1461445618754420

acceptedVersion

Downloaded from Helda, University of Helsinki institutional repository.

This is an electronic reprint of the original article.

This reprint may differ from the original in pagination and typographic detail.

Please cite the original version. 


\title{
'What are you taking away with you?' Closing radio counselling encounters by reviewing progress
}

$$
\begin{array}{r}
\text { Discourse Studies } \\
1-20 \\
\text { C The Author(s) } 2018 \\
\text { Reprints and permissions: } \\
\text { sagepub.co.uk/journalsPermissions.nav } \\
\text { DOI: } 10.1 \text { I } 77 / 146 \text { I4456/8754420 } \\
\text { journals.sagepub.com/home/dis }
\end{array}
$$

\author{
Nataliya Thell \\ Lund University, Sweden
}

\section{Anssi Peräkylä}

University of Helsinki, Finland

\begin{abstract}
Psychological radio counselling is a relatively recent development in psychological practice, where professionals provide psychological help via mass media communication. In the media context, a professional and a help-seeker face a number of communicative challenges, one of which is to close the encounter meaningfully with regard to its counselling and radio tasks. This study explicates how radio counselling encounters can be rounded off by summarising and reviewing the progress achieved in understanding the caller's problem. At the end of the encounters, the radio psychologist invited callers to look back at the conversation and to formulate possible gains from it. On one hand, the radio psychologist encouraged callers' reflection and acknowledged the callers' entitlement to pass judgement on the outcomes of the encounter. On the other hand, the radio psychologist checked and subsequently reviewed the caller's understanding of his or her problem and its solutions. We discuss how the practice was used to round off the encounters in a distinct way with an orientation to their counselling and radio objectives.
\end{abstract}

\section{Keywords}

Conversation analysis, conversation closing, radio counselling, reviewing progress, talk-show therapy

\section{Corresponding author:}

Nataliya Thell, School of Social Work, Lund University, Box 23, 22100 Lund, Sweden.

Email: nataliya.thell@soch.lu.se 


\section{Introduction}

Psychological radio counselling (or radio psychology) represents a professional field of psychological practice - media psychology - where psychologists provide advice on personal problems and transmit psychological knowledge by means of mass media communication. The development of this professional field started in the 1950s, and in the 1980s, media psychology acquired a division status in the American Psychological Association (APA) (Bouhoutsos et al., 1986; Henricks and Stiles, 1989). The radio counselling is typically formatted as a broadcast dialogue (often a call-in) between a professional - a psychologist, a psychotherapist, a psychiatrist or a social worker - and a person seeking help with a troublesome life situation or experience. In the media context, the professional and the help-seeker face a number of communicative challenges, such as how to formulate the problem, and find a solution within a short onetime encounter, and how to make the conversation interesting for radio listeners. One particular challenge is to close this single, short, help-intended conversation meaningfully with regard to its psychotherapeutic goals, limitations of time and the listening audience. This article reports a study of a Swedish radio counselling programme, The Radio Psychologist, ${ }^{1}$ with a particular focus on how conversations between the radio psychologist and callers to the programme are brought to an end. We will start with a description of the setting of the psychological radio counselling, and with a selective review of the current knowledge on conversation closings. We will then outline this study and will proceed to our analysis.

\section{Psychological help on the radio}

Psychological radio counselling is described as a valuable and easily available source of helpful, or at least educational, advice that contributes to creating a positive image of care professionals to the public (Bouhoutsos et al., 1986; Levy, 1989; McGarrah et al., 2009). Counselling broadcasts have been shown to provide emotional and social support, both for those participating in the programmes and for radio listeners (Bouhoutsos et al., 1986; Raviv et al., 1991). As a professional practice, media counselling yet raises ethical concerns and debates on potential dangers of publicly providing help with personal issues (see, for example, McGarrah et al., 2009). Thus, the APA first (in 1977) prohibited the provision of 'personalised advice' on television and radio and later (in 1981) allowed the provision of advice, but decided that psychologists should withdraw from direct therapeutic services in mass media. However, Henricks and Stiles (1989) showed that psychologists' verbal behaviour in American call-in programmes resembled that of cognitively oriented psychotherapists as much as that of educators who would primarily provide guidance and information, and that callers to the programmes shared their thoughts and feelings in a manner similar to that of clients in psychotherapy. The authors suggested that psychological radio call-in programmes represented one of the settings where the process of psychological education and the process of psychotherapy inevitably converged. Likewise, Gaik (1994) has observed that professionals' activities in a therapy talk show comprised a combination of counselling (providing advice and guidance) and therapeutic activities (encouraging introspection and self-analysis). 
From the discursive perspective, the psychological radio counselling combines features of two institutional discourses - psychotherapeutic and counselling interaction, on one hand, and media talk, on the other. In a similar way to psychotherapy and counselling, people get professional help in coping with their problems when they call in to psychological programmes. At the same time, radio counselling encounters differ from conventional psychotherapy and counselling in terms of their principal target - the 'overhearing audience' (Heritage, 1985): the radio encounters are public and thus 'hearable by non co-present persons as somehow addressed to them' (Hutchby, 2006: 15). As a form of media talk, radio counselling falls within the genre of a talk show (Hutchby, 2006). It diverges, nevertheless, from a 'pure entertainment' talk show, where personal matters are usually discussed in a humorous tone, and conversation sometimes borders on gossip (see Martínez, 2003). Yan (2008) suggests that talk-show therapy can be regarded as a distinct genre of discourse and identifies several communicative purposes of televised therapy counselling - that can be generalised to other forms of psychological help in mass media. First, talk-show therapy draws public attention to the issues discussed when publicly exposed, personal problems may become political and social issues. Second, it is a problem-focused discourse, and both those who participate in the programme and get advice and those who watch (or listen to) the programme can benefit from the problem-solving strategies raised. Third, it serves educational and preventive purposes through providing knowledge on psychological dysfunctions and coping strategies. Finally, it has a commercial component: the cases selected for broadcasting are meant to attract an audience and, therefore, contain an interesting and entertaining story. As Yan (2008) concludes, the challenging task of resolving emotional problems gets even more challenging when it is to be done within a one-time encounter that is exposed publicly in a talk-show format.

\section{Conversation closings in mass media and counselling}

In mundane interaction, conversation closings are largely constrained by concerns to maintain sociability. An over-hasty or abrupt exit from a conversation may lead to unwelcome conclusions about the social relationship between interactants - the other's behaviour may be interpreted as disapproval or dislike (Kellermann et al., 1991; Martínez, 2003). Therefore, conversation participants usually negotiate a place in the conversation that would be suitable for the exchange of goodbyes - they seek to mutually agree on the fact that what they are going to do next is cease the interaction (Schegloff and Sacks, 1973).

In institutional contexts, such as doctor-patient interactions, conversation closings are as a rule performed in the ways that correspond to particular institutional tasks. For instance, in the medical setting, the interactional environment for a proper conversation closure may be constituted by the physicians' future arrangements, such as prescription writing (Robinson, 2001). Conversation closings in counselling (and psychotherapy), on one hand, and mass media, on the other hand, have some common features, which they share with other institutional settings: for instance, the closings are structured by constraints of time boundaries (Clayman, 1989). At the same time, they may have divergent, and even contrasting, structural organisations and warrants - due to the divergent goals 
of the encounters. For instance, in news interviews - that aim at seeking information closings are usually brief and straightforward and are warranted by the general procedure of presenting some question or answer as the last one to be undertaken (Clayman, 1989). Interviews in entertainment talk shows, meanwhile, have relatively expanded closings: here, pre-closing work, such as well-wishes and invitations to future shows, attends to the interpersonal framework of the encounters (Martínez, 2003). By contrast, counselling and psychotherapy interaction is built around a project of seeking and providing help, and - when the help is provided within one and only encounter - the participants need to mutually ratify this project as completed in order to bring the encounter to closure (cf. Raymond and Zimmerman, 2016). To mutually coordinate the closing, the conversation participants need to arrive at alignment regarding their respective roles of a help-seeker and a help-provider. For this, the help-seeker may communicate acceptance of the received advice or show satisfaction and thereby indicate that the project of seeking and providing help has been completed (Woods et al., 2015). In cases of lack of alignment with the activity of providing help - for instance, when the advice recipient withholds acknowledgement of the professional's advice - interaction tends to be extended: the professional may proceed with giving advice in pursuit of a congruent response (Heritage and Lindström, 2012; Heritage and Sefi, 1992).

While in news interviews and in entertainment talk shows, it is the professional - the interviewer or the programme host - who has a special right to initiate and manage the closing phase of the encounter (Clayman, 1989; Martínez, 2003); in advice-giving environments, this may be rather the help-seeker's obligation and interactional privilege (Stommel and Te Moulder, 2015). In the comparative study of counselling online and over the phone, Stommel and Te Moulder (2015) have found, for instance, that in telephone consultations, call closings were overwhelmingly initiated by the callers who explicitly acknowledged received advice. In online consultations, however, chat closings regularly lacked an advice acknowledgement, and the counsellors faced a dilemma: they did not have the epistemic right to claim that the client had received sufficient help, and at the same time, they could not exit the chat session without respecting the caller's privilege to acknowledge the advice. The counsellors solved the dilemma by eliciting an advice acknowledgement with pre-closing questions that projected the client's future actions ('Does that give you something to work with?'), elicited direct advice acknowledgement ('I hope you know enough now') or offered a new advice sequence ('Do you have any other questions?').

Similarly, conversation closings in radio counselling seem to be contingent upon acknowledgement of the help received. For instance, Ten Have (1978), in his study of a Dutch counselling radio programme with a non-expert host-counsellor, observed that conversation closings mostly immediately followed advice acceptance. In the call-ins, it was the caller who was to initiate the closing sequence by indicating his or her satisfaction. When callers did not display satisfaction, calls were lengthened, and at the end, the host could enforce a closing. Likewise, in the study of a British radio advice call-in on welfare matters, Hutchby (2006) observed that the programme host could elicit an advice acknowledgement by asking the caller whether he or she has found the professional's advice helpful ('D'you find that helpful Margery?'). In such a way, the host brought conversation to closure and, at the same time, handled the tension between the 'personal' 
and the 'public' dimensions of advice giving on the radio: the host made a shift from experts' talk on more general themes and issues that could be of interest for the broad radio audience, to the individual situation of the caller.

\section{Closure and therapeutic goals}

When a radio dialogue between a psychotherapist and a caller is extended and explorative, it may be comparable to condensed forms of psychotherapy, where the therapeutic relationship is established, accomplished and rounded off within one encounter (Seiving, 2015; for discussion of single-session psychotherapy, see Cameron, 2007; Harper-Jaques and Foucault, 2014). For instance, Hodges (2002), in his study of a British therapeutic radio call-in programme, found that the goal of the radio encounters was not to solve callers' problems but to restructure them by shifting the locus of concern to the relationship with oneself. This is similar to more conventional forms of psychotherapeutic work, where a central element is a re-formulation of the client's initial version of his or her problem (Davis, 1986; see also Antaki et al., 2005). Thus, a closing phase of a radio counselling encounter may also incorporate rounding off a psychotherapeutic process, which constitutes a distinct phase of therapeutic work.

A recent discussion calls attention to the fact that ending a therapeutic relationship is an important part of psychotherapeutic work while there is 'almost complete lack of research and clinical discussion on this topic in the literature' (Hilsenroth, 2017: 1). Theoretical discussions and studies of psychotherapists' self-reports have identified such tasks in the final phase of the therapeutic work: solidifying gains and improvements, making the client feel praised and helped, shifting the focus of talk to discussing therapeutic experience and change, framing personal development as invariably unfinished and collaboratively developing a future plan for the client's growth (Fragkiadaki and Strauss, 2012; Goode et al., 2017; Hill, 2005; Maples and Walker, 2014; Norcross et al., 2017). Remarkably, reports of experienced psychotherapists revealed commonality in termination behaviour across theoretical orientations and individual practitioners (Norcross et al., 2017). Activities aimed at reviewing the course of treatment and discussing the client's affective reactions to termination were also found to be an essential component of successful short-term psychological counselling (Quintana and Holahan, 1992).

The question is then if and how these therapeutic goals may be oriented to in psychological radio counselling. In this study, we explicate a practice used to round off the encounters by reviewing the progress achieved in understanding and solving callers' problems. The practice was used to shift the focus of the dialogue to a discussion of gains, and a formulation of conclusions, as well as to check and rectify the caller's understanding of the problem formulation and solutions. We will first describe the data and analysis and then consider the therapeutic functions of the practice in the discussion section.

\section{Data and method}

The data come from the Swedish programme The Radio Psychologist (Radiopsykologen), which has been broadcast once a week on a state radio channel since 2009 . In the programme, a certified psychotherapist, called a radio psychologist, performs a double role: 
the programme host, who greets listeners and introduces callers, and the expert, who provides help in understanding painful or confusing experiences and solving troublesome situations. The study is based on publicly available recordings of programme episodes that were broadcast during 2014-2015. In total, 85 episodes were broadcast during this period, of which 79 were included into the data corpus. Six episodes were excluded from the data because they did not contain an interactive dialogue with a caller seeking help: in two of the episodes, the radio psychologist answered listeners' letters, and in the other four, callers told of how they had coped with their problems (and thus did not seek help for them). The programme episodes lasted for 29 minutes each and consisted of the radio psychologist's introductory words, a telephone conversation with the caller and the radio psychologist's closing words, where he invited radio listeners to respond to the programme by phone or via the Internet. To participate in the programme, radio listeners could contact the programme by ringing in, or sending an email or a letter by post, and programme producers contacted them afterwards to arrange a conversation with the radio psychologist. Although the programme was not arranged as a phone-in and the conversations were recorded in advance, we refer to the listeners participating in the programme as 'callers' due to their initiating role in contacting the programme to take part in it.

The broadcast conversations between the radio psychologist and the callers were edited versions of the original conversations that lasted from 45 minutes to about an hour. Two programme producers performed the editing that aimed at shortening the conversations to a broadcastable length of about 25 minutes and, at the same time, preserving their coherence so that they could be heard as if they were happening in real time. With the concern to preserve caller anonymity, the producers cut out the segments in which the callers happened to reveal too much personal information, such as making their hometown or a relative recognisable. In addition, they removed sections that could be perceived as being too sensitive, such as with a lot of crying, as well as passages considered monotonous or repetitive. At the same time, pauses and silences were preserved and could be much longer than in other types of broadcasts (up to 10-15 seconds). Generally, the broadcast versions aimed to reproduce three phases of the original conversations, which reflected the dynamics of the dialogues: identification of the caller's problem, discussion of possible ways to understand and solve the problem, and closing with a summary of achievements. Although the closings were not formally scripted, there seemed to be an implied understanding between the radio psychologist and the producers that the encounters should be closed with a summary of gains or change in the caller that could be described as 'a happy ending' ${ }^{2}$ Conversation closings were thus the part of the conversations that was likely to be well preserved in the broadcast versions. Still, the fact that we do not have access to the original unedited conversations is a limitation of this study. To deal with this limitation, we complemented the data set with several programme episodes from earlier years, when the programme was formatted as a phone-in and the conversations between the radio psychologist and callers were broadcast live. When proceeding with the analysis, we used this material to probe our observations. In addition, those extracts, which we suspected as such that could have been shortened, were treated with caution.

We draw upon the method of conversation analysis (CA; see, for example, Sidnell, 2010), which has been chosen due to its potential to explicate how communicative and institutional concerns are dealt with in interaction (e.g. Arminen, 2005). In accordance 
with CA research procedure, initial exploration of a large corpus of data yielded identification of recurrent patterns of interaction, which resulted in identifying an interactional phenomenon for closer examination. The excerpts containing the identified practice were collected and transcribed according to conversation analytical transcription conventions (see Appendix 1 for a legend to the transcription symbols; for transcription conventions, see, for example, Hepburn and Bolden, 2013). The analysis then proceeded through case-by-case comparison, towards a detailed description of the practice and its interactional conditions and consequences.

\section{Analysis}

Conversations between a psychotherapist and a caller in The Radio Psychologist were routinely closed by the exchange of thanks and goodbyes. This terminal exchange was preceded by substantial preparatory work, which was more extended than in other media contexts, such as news interviews and entertainment talk shows (cf. Clayman, 1989; Martínez, 2003). The conversations were rounded off in two principal ways, one of which is in the focus of this article. In about half of the conversations studied $(\mathrm{N}=41$; these will not be our primary focus), radio psychologist and caller seemed to arrive at a concrete solution to the caller's problem, usually in the form of the radio psychologist's advice, for instance, to write a letter to the other conflicting party or to seek further help in more conventional forms of psychotherapy and counselling. The final part of these conversations was built around the caller's question 'What shall I do?' and the radio psychologist's advice and guidance - the work that characterises counselling mode of a psychological talk show (Gaik, 1994). In these cases, the closure was made relevant when either the caller accepted the advice and displayed readiness to follow it, or the radio psychologist elicited an advice acknowledgement by asking, for example, 'Do you think you can take this away with you?' or 'Is this useful for you?'. Closure did not, however, immediately follow the caller's advice acknowledgement (cf. Stommel and Te Moulder, 2015; Ten Have, 1978). In response, the radio psychologist would elaborate and clarify the advice. Prior to the terminal exchange, the radio psychologist often additionally asked about emotional effect of the dialogue: 'In comparison to when we started talking, how do you feel now?' or 'What do you feel right now when we are closing?'. Callers answered with a report on the change in their emotional state for the better, such as feeling calmer or more optimistic.

In the other half of the episodes $(\mathrm{N}=38)$, the dialogues had a more diffuse character: the participants did not arrive at a particular solution to the caller's problem but continued to explore different explanations and possible remedies until one of them (most often the radio psychologist) signalled that it was time to end the encounter. The dialogues were then rounded off by revisiting interpretations and solutions discussed earlier in the conversation. This work was initiated by the radio psychologist's question that invited a caller to reflect upon what he or she had learned in the encounter. The most frequent formulation of the question $(\mathrm{N}=23)$ was a colloquial metaphorical phrase, 'What are you taking away with you?' (Swedish: 'Vad tar du med dig?'), ${ }^{3}$ and its variations such as 'What have you got with you (from this conversation)?'. A less frequent wording could be, for instance, 'Where are you now (in your thoughts and feelings after this conversation)?'. These 
questions allowed singling out and re-invoking particular elements of the conversation's contents through encouraging the caller's reflective feedback. The conversations were thus brought to a close by sustaining a focus on callers' self-expression and self-reflection, which is a characteristic feature of therapy talk (Ten Have, 1989). These closings - more therapeutic by their character - are the focus of this study.

The Swedish question, 'Vad tar du med dig?', and its English equivalent are mentioned in care practitioners' and management literature as relevant for closing environments: they can be used to summarise and to evaluate activities, such as an educational course, an intervention or a department meeting (Zetterqvist et al., 2013: 17; Sawicki, 1990: 201; Henderson et al., 2014: 31). In both Swedish and English, this question can also be used to round off conventional therapeutic sessions with the aim to increase collaboration and interpersonal sensitivity between a therapist and a client (J. Wahlström, personal communication, 2016; Wills and Sanders, 2013: 32). In contrast to more cognitively oriented formulations, such as 'What was the most important in the conversation?', the question 'What are you taking away with you?' may be heard as requesting a description of thoughts as well as feelings. In our data, the two radio psychologists participating in the programme - a female trained in cognitive-behavioural therapy and a male trained in psychodynamic and interpersonal therapies - both used the question to invite callers to look back at the encounters and reflect upon their gains. In response, the callers re-invoked problem explanations and solutions discussed earlier in the dialogues, and subsequently, the radio psychologist could either approve or rectify the understandings displayed by the callers.

\section{Eliciting reflective feedback}

Extract 1 comes from a conversation where the caller complained of pain in the solar plexus, which he thought was caused by anxiety. He did not know why he felt worried, however. The radio psychologist and the caller discussed how the anxiety could be connected to changes in the caller's life due to his age and approaching retirement. About a minute before the excerpt, the radio psychologist announced that it would soon be time to stop the conversation:

Extract $1^{4}$

12.06 .2014

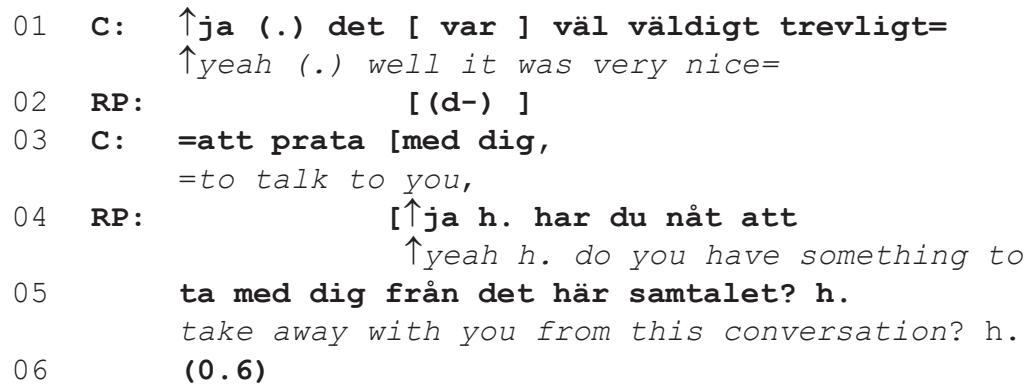




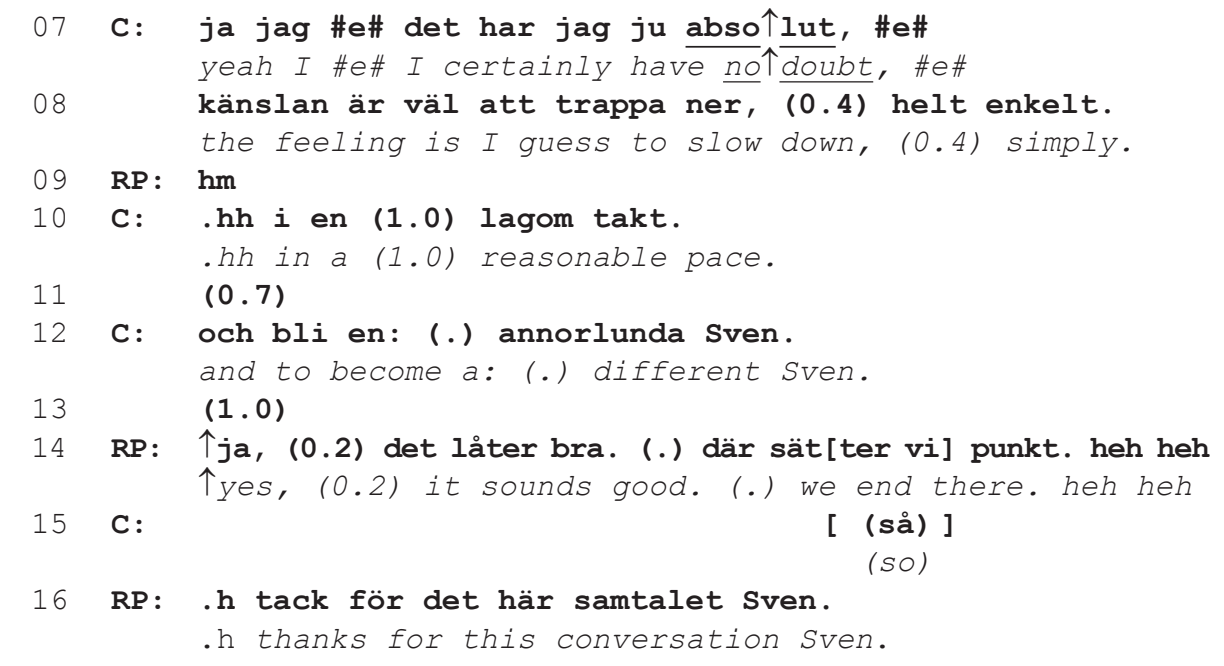

The caller's display of appreciation in the form of the assessment, 'it was nice to talk to you' (lines 1 and 3), is closing implicative: it makes it possible for the radio psychologist to respond with a reciprocal expression of appreciation ('it was nice to talk to you too'), after which the conversation participants could move to an exchange of 'thank you' and 'goodbye'. Instead, after displaying alignment with the caller by replicating the caller's high-pitched 'yeah' (compare lines 1 and 4), the radio psychologist pursues a recital of what the caller has gained from the dialogue (lines 4-5), implying that the conversation will not be treated as just any 'nice talk' (lines 1 and 3 ) but as a discussion that has had the specific aim of helping the caller.

Although, in this case, the question is designed to project a yes/no answer (lines 4-5), the caller responds to it as if it comprised a what-inquiry and provides an extended response (lines 8-12). The caller starts his answer with affirmation and by reassuring that he does have something to 'take away with him' (line 7). The design of the affirmation - by inclusion of the emphasised 'no $\uparrow \mathrm{doubt}$ ' - is oriented to a possibility that the question could have implied that there would not be anything to take away. Then the caller refers to topics discussed earlier in the conversation: about considering working less due to his age (line 8), the possibility of reducing his workload gradually (line 10) and finding other ways of maintaining his social identity (line 12) than the 'symbolic value of work' (cf. Hockey and James, 1993: 143). These takeaways describe possible solutions to the caller's problem in the form of intentions for the particular actions. At the same time, they display the understanding of the caller's problem that has been achieved in the dialogue (cf. Emerson and Messinger, 1977) while skipping the reasoning trajectory that led to the particular problem formulation (cf. Thell and Jacobsson, 2016: 36-37). After the radio psychologist's positive assessment of the caller's conclusions, and announcement 'we end there' (line 14), the participants move to exchange of thanks (starting in line 16) and goodbyes (not shown).

Extract 2 is from a conversation between the radio psychologist and a female caller who had not had contact with her father for about 25 years. The caller contacted the 
programme after she received a letter from her father who wanted to meet her and her children, and she felt unsure about how to respond to the letter:

Extract 2

\subsection{1 .2014}

01 RP: .hhh vi kanske inte blir så mycket klokare just nu då, .hhh maybe we can't get so much wiser right now then,

02 C: NEJ, (.) jag tyc[ker det e] (0.2) har kommit NO, (.) I think it is (0.2) has come

03 RP: [ mhuh ]

04 C: långt $\mathrm{f}(\mathrm{h}) \operatorname{ram}(\mathrm{h})$. [heh heh] heh ändå:, (.) a long way $f(h)$ orward(h). heh heh heh after all:, (.)

05 RP: [ $\mathrm{mm}$ ]

06 C: a så (.) a så jag tycker det här (.) e, (0.2) that is (.) that is I think this one here (.) is, (0.2)

07 känns som (.) jag har nånting å gå vidare med. feels as if (.) I have something to move on with.

08 RP: $\mathrm{mm}$.h så vad tror du att du tar med dig då? $\mathrm{mm}$.h so what do you think you are taking away with you then?

09 C: .hh a jag tar med mig just de här, (.) .hh well I am taking with me exactly these, (.)

10 den här tanken om, (.) att det beror på this thought about, (.) that it depends

11 >så att säga<. att jag får fundera vidare på det. [.hhh

12 RP:
130 to say<. that I shall consider this further. [hhh
[mm

13 C: och \#e:\# jag känner mig rätt så (0.5) nöjd

and \#e:\# I feel quite (0.5) pleased

14 med att kunna tänka runt det. that I can think about it.

15 RP: $\mathbf{m m}$

16 C: just nu (.) känns det som om det e det e right now (.) it feels as if it is it is

17 <en bra utgångspunkt> för mig. .hh $<$ a good starting point $>$ for me. .h

In line 1, the radio psychologist suggests to round off the encounter: 'maybe we can't get so much wiser right now'. In response, the caller agrees (line 2) and provides further grounds to finish the dialogue: she asserts that the conversation 'has come a long way forward' and that she has got 'something to move on with' (lines 2-7). Thereby, an understanding of the conversation being exhausted for the time being is displayed, which makes conversation closure relevant. In lines 2-7, the caller expresses appreciation for the help received and thus displays satisfaction with the encounter. Still, the radio psychologist invites the caller to reflect upon more specific takeaways (line 8).

In this case, the radio psychologist's question in line 8 is constituted by its placement and design (prefaced by so and ending with then) as a query arising from what 
the caller said immediately before, in line 7 ('feels as if I have something to move on with'). While in her prior turn the caller described a general effect of the conversation and referred to a vague 'something' that she can move on with (line 7); in her response to the question on takeaways, the caller mentions a particular element of the dialogue's content - 'thought that it depends' (line 10). Here, the caller refers to the radio psychologist's advice, formulated earlier in the conversation - to wait with a decision on whether to re-establish contact with the caller's father and to answer his letter by saying that 'it depends'. The caller recycles the radio psychologist's expression and thus acknowledges the advice received. This move further contributes to creating the interactional environment relevant for ending the project of providing help and consequently makes closing the encounter warranted and mutually resolvable (cf. Stommel and Te Moulder, 2015).

The caller's response in lines 9-17 is designed as a clause containing a phrasal answer (cf. Fox and Thompson, 2010), that is, the caller does not start by naming her takeaways right away but incorporates elements of the question in her response turn first: 'I am taking away with me ... '. This prefaced, 'phrase-in-clause' feature of the response may indicate difficulty in producing an answer due to a problematic nature of the course of action initiated by the question (cf. Fox and Thompson, 2010; Schegloff and Lerner, 2009). The difficulty may have to do with the challenging constraints the radio psychologist's question imposes. First, the question invites a change to a reflective mode - to look back at the conversation and single out something from it - which may require a cognitive effort. Second, the question requests a description of the beneficial achievements of the dialogue and thus invites an upshot of the conversation that would incorporate an appreciation of the help received. The caller responds to this implication when she explicitly evaluates elements of the dialogue as useful ('I feel quite pleased', in line 13, and 'it is a good starting point', in lines 16-17). Hereby, the question-answer sequence sums up the conversation in a distinct way: it re-invokes elements from earlier in the conversation, which are brought up as helpful and appreciated.

\section{Reviewing caller's understandings}

In the majority of cases $(\mathrm{N}=30)$, the radio psychologist responded to the callers' descriptions of takeaways by approving, complementing or revising them and, occasionally, by providing a gist of the caller's conclusions ('it sounds as if you have a plan') or by highlighting a part of them. For instance, in Extract 1, shown above, the radio psychologist responds to the caller's upshot with a positive assessment (line 14). While the assessment closes the sequence (Schegloff, 2007: 123-126), it also displays the radio psychologist's approval of the caller's conclusions. By demonstrating approval, the radio psychologist assumes the expert (authority) position and treats the caller's upshot as a candidate understanding which is subject to either ratification or revision (cf. Stevanovic and Peräkylä, 2012).

Extract 3 provides an example of the radio psychologist's extended response to the caller's takeaways, in which he adds new elements to the caller's conclusions (lines 13-19). The extract shows one of the few instances in our data, where it was 
a caller who highlighted the relevance of the conversation's closing (line 1). Initially, the caller formulated his problem as a longing for close friendship - a relationship where he could share his experiences and feel secure. In the conversation, his problem was reformulated into sacrificing his own needs for the sake of others:

Extract 3

\subsection{3 .2015}

01 C: MEN MEN, (0.7) nu måste jag snart åka till skolan. WELL WELL, (0.7) now I must soon go to school.

02 RP: hmh okej. HEH heh heh hmh okay. HEH heh heh

03 C: huh huh

$04 \quad(0.7)$

05 RP: .hh så vad tar du med dig nu då? .hh so what are you taking away with you now then?

$06 \quad(0.6)$

07 RP: €på väg till plugget. $€$ $€$ €n your way to the school. $€$

$08 \quad(0.8)$

09 C: jag tar med mig att:s:h (0.6) .hh $\uparrow J A$, hh. .hh I am taking with me that:s:h (0.6) .hh 个YEAH, hh. .hh

10 vara mer (0.2) .hh mig själv, (0.8) å tänka mer på mig själv. to be more (0.2) .hh myself, (0.8) and think more about myself.

11 RP: hm:,

$12 \quad(1.2)$

13 RP: du har kraften å du har drivet, (0.4) you have your strength and you have your energy, (0.4)

14 du har tankarna, (0.5) du har tillgång till det du känner, you have your thoughts, (0.5) you have access to what you feel,

$15 \quad(0.5)$

16 RP: .hhh och för att vara sjutton år (.) det e inte så många .hhh and for one who is seventeen (.) there are not so many

17 sjuttonåringar som har hört av sig hit, seventeen-year-olds who have gotten in touch with us,

18 C: НнНнH .

19 RP: å de- (.) å det säger en hel del. and $i-$ (.) and it says a great deal.

The caller responds to the radio psychologist's question (line 5) after a considerable delay. The caller's first opportunity to answer is in line 6, but as he does not take it, the radio psychologist pursues the question in line 7 . Even then, the caller's answer is delayed by silence (line 8) and the recycled question formulation ('I am taking with me', in line 9; for a similar structure, see also Extract 2, line 9). The delay and the high-pitched 'yeah' (line 9) following it display the caller's effort and eventual success in finding the answer. In line 10, the caller produces his answer with a description of a change in his 
conduct that would be a solution to his problem. This solution characterises the caller's problem in terms of how he treats himself, rather than how he treats others - the latter was the caller's initial description of his problem at the start of the conversation. Despite reflecting the problem formulation the participants have achieved, the answer remains on a rather unspecific level.

After a minimal acknowledgement (line 11) and a silence (line 12), the radio psychologist responds with a comment (lines 13-14), which is designed as an elaboration of the caller's conclusions. In this elaboration, the radio psychologist praises the caller's capacities, thereby implying that the focus on himself to which the caller referred is indeed justified, and adds a new aspect to the caller's summary - a description of resources the caller has to achieve the required change and to cope with his problem. In lines 16-17 and 19, the radio psychologist provides evidence for the caller's potential and abilities - he is one of the few in his age group who have contacted the programme. Thus, the radio psychologist complements the caller's understanding of the conclusions to be drawn from the dialogue.

While Extract 3 provides an example of the radio psychologist's extended affiliative response to the caller's takeaways, the next extract illustrates how the radio psychologist could disagree with at least part of a caller's conclusions. Disagreement is a significant component of therapeutic work (Viklund et al., 2010) and may be used by therapists to increase clients' awareness and to challenge their problematic cognitive and emotional patterns (Weiste, 2015). In Extract 4, the radio psychologist disagrees with a caller in order to modify the conclusions she draws from the discussion. In this conversation, the caller's concern was about her relationship with her partner and his children from his previous marriage:

\section{Extract 4}

\subsection{1 .2014}

01 RP: okej, jag föreslår att vi stannar där. okay, I suggest that we stop there.

02 C: $\mathbf{m m}$

03 RP: vad tror du att du tar med dig? what do you think you are taking away with you?

$04 \quad(2.5)$

05 C: .hh (.) jag tycker väl att det är det här som hh. .hh (.) I guess I think that it is this that hh.

06 vi kom fram till det sista här att: att vi vi (0.5) we arrived at this last point here that: that we we (0.5)

07 måste vara väldigt lyhörda för (.) oss, (.) det vi vill, must be very responsive to (.) us, (.) what we want,

$08 \mathrm{RP}: \mathrm{hm}$

09 C: jag tycker det är rätt och riktigt. h. (0.2)

I think this is right and proper. h. (0.2)

10 .hh och så att vi skulle kunna ha den här (.) att vi .hh and so that we could have this (.) that we 


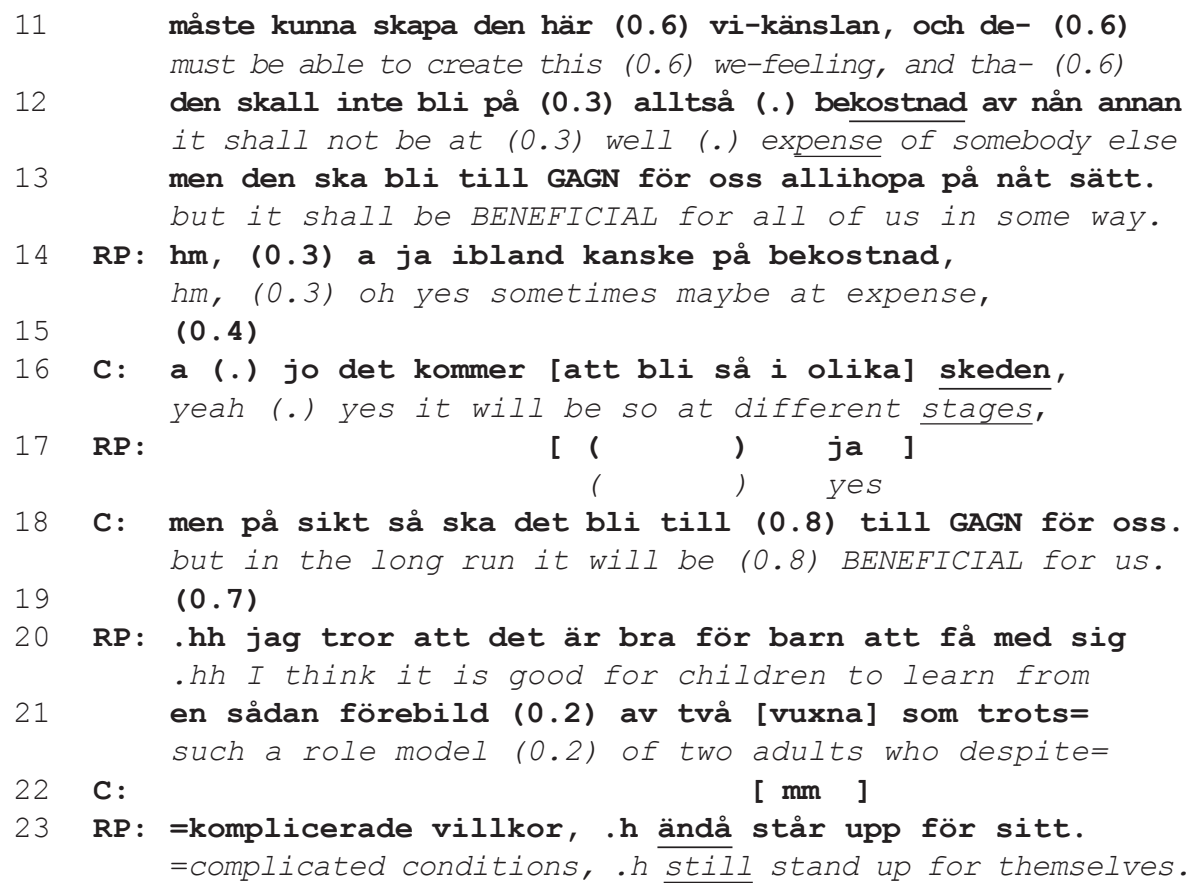

After closing the discussion of the caller's problem (line 1) and thereby signalling the approach of the closure, the radio psychologist invites the caller to formulate conclusions (line 3). The caller responds by describing possible solutions to her problem (lines 6-13). The caller's description 'to be very responsive to us' (line 7) refers to the radio psychologist's recommendation not to allow the partner's children to overshadow the caller's relationship with her partner. The positive evaluation 'this is right and proper' (line 9) implies, therefore, an appreciation of the radio psychologist's advice.

In his response to the caller's takeaways, the radio psychologist first neutrally acknowledges the caller's talk with ' $\mathrm{hm}$ ' and then disagrees with a part of the caller's statement: 'sometimes maybe at expense' (line 14). While the caller maintains that there can be a solution that is good for everybody (lines 12-13), the radio psychologist calls into question such harmony by suggesting that the solution may indeed be at somebody's expense (line 14). Thus, the radio psychologist's response partly redefines the caller's understanding of the ramifications of the suggested course of action. In the ensuing dialogue (lines 16-23), the participants make moves that seem to aim at (yet not fully achieve) an agreement. The radio psychologist eventually suggests that the partner's children might also benefit from seeing the couple standing up for their relationship, thereby yielding to a modified version of the caller's initial understanding of the harmony in the relationship.

The nature of the radio psychologists' responses to callers' takeaways reveals an asymmetry in the conversation participants' entitlement to know about and deciding on the outcomes of the conversations. On one hand, the caller is in the position of helpseeker and, therefore, has a priority in passing judgement on the help received. The radio 
psychologist orients to this entitlement and acknowledges it when he asks the caller to single out elements of the conversation's contents that he or she found useful. On the other hand, the content of what is to be taken away becomes subject to negotiation between the radio psychologist and the caller due to the radio psychologist's role of expert on psychological issues, including the caller's problem.

\section{Discussion and conclusion}

In The Radio Psychologist, closing sections of the encounters with a psychotherapist were extended and oriented to the task of a collaborative completion of a project of providing help. The encounters could be rounded off with principal orientation to their counselling goals (seeking and providing advice), as well as in a more therapeutic mode when callers were invited to reflect upon and formulate possible gains. We focused on this second group of cases, where the closing parts of the encounters were not built around the radio psychologist's particular advice, but where the caller was asked to single out those contents of the encounter that he or she found useful. By asking a caller to formulate conclusions, the radio psychologist, on one hand, acknowledged the callers' entitlement to pass judgement on the outcomes of the encounter, while, on the other hand, he or she checked and reviewed the caller's understanding of the problem and its solutions. When re-invoking materials from earlier in the conversation, the caller displayed his or her understanding of them, and the radio psychologist could either approve this understanding or complement and modify it.

The radio psychologist's request to the caller to formulate conclusions was expressed in such a way so as to elicit a type of summary of the conversation that would incorporate an appreciation for the help received. In the description of their takeaways, the callers referred to the radio psychologist's explanations and advice from earlier in the conversation and, in such a way, acknowledged the professional's input into understanding and solving the problem. The acknowledgement could also be accompanied by an explicit display of appreciation for particular advice or explanations. Thus, the closing relevant environment was established by re-invoking materials from earlier in the conversation (cf. Schegloff and Sacks, 1973), as well as by bringing up these materials as helpful and appreciated and thus indicating the help-seeker's satisfaction with the help received (cf. Raymond and Zimmerman, 2016). The radio psychologist also invited the caller to describe takeaways after the caller had expressed a general positive assessment of the conversation ('it was nice to talk to you') or portrayed the conversation as helpful in general terms ('I have now something to move on with') to specify and review the gains achieved.

The invitation to the caller to reflect upon gains from the encounter and the subsequent review of the caller's understandings seem to be in line with several tasks of the ending phase of therapeutic process that have been described in the literature (see Fragkiadaki and Strauss, 2012; Hill, 2005; Maples and Walker, 2014): it shifts the focus to processing and reviewing progress, summarises and solidifies gains of the encounter, prepares the caller to dealing with his or her problem after the encounter is finished and may make the caller feel helped through framing his or her experience of the encounter as such where the caller has got something to take away 
with him or her. Besides, the practice serves to trace change in the help-seeker's perspective of his or her problem and to monitor the effect of the professional's interventions.

The fact that the encounters' endings are considered to be one of the elements included in the edited versions of the conversations with the radio psychologist suggests that callers' formulations of takeaways are regarded to be of interest to the radio listeners, and in line with the radio objectives of the encounters. First, the explicit acknowledgement of the helpful achievements of the conversation with the radio psychologist constructs the understanding of the encounter as helpful and thus, dramaturgically, creates a successful story or a story with a happy ending. Second, the caller's conclusions with an explicit description of the benefits of the encounter may be of use to the radio listeners who identify themselves with the caller and experience similar problems. In the caller's answer to the question about takeaways, the listeners get a straightforward message about which interpretations and recommendations the caller has found especially helpful in coping with the particular problem. Besides, the conversation is rounded off in a way that delineates its meaningfulness as a help-providing encounter. One of the educational tasks of psychological programmes in media is to create a positive image of psychological and psychotherapeutic professions (Bouhoutsos et al., 1986; McGarrah et al., 2009), and the explicit reference to the benefits of the radio conversations with a psychotherapist may serve this goal by exemplifying the ways in which this particular type of professional may be of help.

\section{Acknowledgements}

We would like to express thanks to the participants of the Analysis seminar (Lund, 2015) and Semiosis workshop (Helsinki, 2015) for insights into the data, and to the discussants of earlier ideas of the paper at the 8th European Conference on Psychotherapy Research (Klagenfurt, 2015) and the 4th Nordic Interdisciplinary Conference on Discourse and Interaction (Oslo, 2016) for questions and comments. We are grateful to Shirley Näslund, Katarina Jacobsson and Liisa Voutilainen for commenting on earlier drafts of the paper. Our sincere thanks are due to William B. Stiles and Anna Lindström for their critical reading and helpful suggestions.

\section{Declaration of conflicting interests}

The author(s) declared no potential conflicts of interest with respect to the research, authorship, and/or publication of this article.

\section{Funding}

The author(s) received no financial support for the research, authorship and/or publication of this article.

\section{Notes}

1. The Swedish name of the programme is Radiopsykologen. The programme is broadcast by the radio channel $\mathrm{P} 1$.

2. The description 'a happy ending' belongs to one of the programme producers (interview with the programme producer, 25 February 2015).

3. We have translated the Swedish colloquial phrase 'Vad tar du med dig?' (word-by-word 
translation 'What take you with you?') using the formulation 'What are you taking away with you?' to keep the wording as close to the original as possible and to choose the closest colloquial equivalent in English. The question could be alternatively translated as 'What are you taking home with you?' or even 'What have you learned from this conversation?'.

4. The translation of the original Swedish transcripts into English has been performed in such a way so as to try to preserve the original word order, grammar and lexical choices as much as possible and at the same time, to make the translation comprehensible. The second line with word-by-word translation (even though advisable, see for example, Nikander, 2008) has been omitted due to the fact that we do not make analytical points of particular lexical or grammatical choices in the data.

\section{References}

Antaki C, Barnes R and Leudar I (2005) Diagnostic formulations in psychotherapy. Discourse Studies 7(6): 627-647.

Arminen I (2005) Institutional Interaction: Studies of Talk at Work. Aldershot: Ashgate Publishing.

Bouhoutsos JC, Goodchilds JD and Huddy L (1986) Media psychology: An empirical study of radio call-in psychology programs. Professional Psychology: Research and Practice 17(5): 408-414.

Cameron CL (2007) Single session and walk-in psychotherapy: A descriptive account of the literature. Counselling and Psychotherapy Research 7(4): 245-249.

Clayman SE (1989) The production of punctuality: Social interaction, temporal organization, and social structure. American Journal of Sociology 95(3): 659-691.

Davis K (1986) The process of problem (re)formulation in psychotherapy. Sociology of Health \& Illness 8(1): 44-74.

Emerson RM and Messinger SL (1977) The micro-politics of trouble. Social Problems 25: 121-134.

Fox BA and Thompson SA (2010) Responses to wh-questions in English conversation. Research on Language and Social Interaction 43(2): 133-156.

Fragkiadaki E and Strauss SM (2012) Termination of psychotherapy: The journey of 10 psychoanalytic and psychodynamic therapists. Psychology and Psychotherapy: Theory, Research and Practice 85(3): 335-350.

Gaik F (1994) Radio talk-show therapy and the pragmatics of possible worlds. In: Duranti A and Goodwin C (eds) Rethinking Context. Cambridge: Cambridge University Press, pp. 271-289.

Goode J, Park J, Parkin S, et al. (2017) A collaborative approach to psychotherapy termination. Psychotherapy 54(1): 10-14.

Harper-Jaques S and Foucault D (2014) Walk-in single-session therapy: Client satisfaction and clinical outcomes. Journal of Systemic Therapies 33(3): 29-49.

Henderson P, Holloway J and Millar A (2014) Practical Supervision: How to Become a Supervisor for the Helping Professions. London; Philadelphia, PA: Jessica Kingsley Publishers.

Henricks WH and Stiles WB (1989) Verbal processes on psychological radio call-in programs: Comparisons with other help-intended interactions. Professional Psychology: Research and Practice 20(5): 315-321.

Hepburn A and Bolden GB (2013) The conversation analytic approach to transcription. In: Sidnell J and Stivers T (eds) The Handbook of Conversation Analysis. Oxford: WileyBlackwell, pp. 57-76.

Heritage J (1985) Analysing news interviews: Aspects of the production of talk for an overhearing audience. In: van Dijk T (ed.) Handbook of Discourse Analysis: Discourse and Dialogue, vol. 3. London: Academic Press, pp. 95-117. 
Heritage J and Lindström A (2012) Advice giving - terminable and interminable: The case of British health visitors. In: Limberg H and Locher MA (eds) Advice in Discourse (Pragmatics and Beyond New Series). Philadelphia, PA: John Benjamins, pp. 169-194.

Heritage J and Sefi S (1992) Dilemmas of advice: Aspects of the delivery and reception of advice in interactions between health visitors and first time mothers. In: Drew P and Heritage J (eds) Talk at Work. Cambridge: Cambridge University Press, pp. 359-417.

Hill CE (2005) Therapist techniques, client involvement, and the therapeutic relationship: Inextricably intertwined in the therapy process. Psychotherapy: Theory, Research, Practice, Training 42(4): 431-442.

Hilsenroth MJ (2017) An introduction to the special issue on psychotherapy termination. Psychotherapy 54(1): 1-3.

Hockey J and James A (1993) Growing Up and Growing Old: Ageing and Dependency in the Life Course. London: SAGE.

Hodges I (2002) Moving beyond words: Therapeutic discourse and ethical problematization. Discourse Studies 4(4): 455-479.

Hutchby I (2006) Media Talk: Conversation Analysis and the Study of Broadcasting. Glasgow: Open University Press.

Kellermann K, Reynolds R and Chen JB (1991) Strategies of conversational retreat: When parting is not sweet sorrow. Communication Monographs 58: 362-383.

Levy DA (1989) Social support and the media: Analysis of responses by radio psychology talk show hosts. Professional Psychology: Research and Practice 20(2): 73-78.

McGarrah NA, Alvord MK, Martin JN, et al. (2009) In the public eye: The ethical practice of media psychology. Professional Psychology: Research and Practice 40(2): 172-180.

Maples JL and Walker RL (2014) Consolidation rather than termination: Rethinking how psychologists label and conceptualize the final phase of psychological treatment. Professional Psychology: Research and Practice 45(2): 104-110.

Martínez ER (2003) Accomplishing closings in talk show interviews: A comparison with news interviews. Discourse Studies 5(3): 283-302.

Nikander P (2008) Working with transcripts and translated data. Qualitative Research in Psychology 5(3): 225-231.

Norcross JC, Zimmerman BE, Greenberg RP, et al. (2017) Do all therapists do that when saying goodbye? A study of commonalities in termination behaviors. Psychotherapy 54(1): $66-75$.

Quintana SM and Holahan W (1992) Termination in short-term counseling: Comparison of successful and unsuccessful cases. Journal of Counseling Psychology 39(3): 299-305.

Raviv A, Raviv A and Arnon G (1991) Psychological counselling over the radio: Listening motivations and the threat to self-esteem. Journal of Applied Social Psychology 21(4): 253-270.

Raymond G and Zimmerman DH (2016) Closing matters: Alignment and misalignment in sequence and call closing in institutional interaction. Discourse Studies 18(6): 716-736.

Robinson JD (2001) Closing medical encounters: Two physician practices and their implications for the expression of patients' unstated concerns. Social Science \& Medicine 53(5): 639-656.

Sawicki L (1990) Meetings as vehicles of communication. Journal of In-Service Education 16(3): 200-203.

Schegloff EA (2007) Sequence Organization in Interaction: A Primer in Conversation Analysis, vol. 1. Cambridge: Cambridge University Press.

Schegloff EA and Lerner GH (2009) Beginning to respond: Well-prefaced responses to Wh-questions. Research on Language and Social Interaction 42(2): 91-115. 
Schegloff EA and Sacks H (1973) Opening up closings. Semiotica 8(4): 289-327.

Seiving CA (2015) 'Vad vill du ha min hjälp med?' - En deskriptiv studie av radiopsykologens terapeutiska samtal ['What do you want me to help you with?' - A descriptive study of the radio psychologist's therapeutic conversation]. Master's Thesis, Department of Psychology, University of Gothenburg, Gothenburg.

Sidnell J (2010) Conversation Analysis: An Introduction. Oxford: Wiley-Blackwell.

Stevanovic M and Peräkylä A (2012) Deontic authority in interaction: The right to announce, propose, and decide. Research on Language and Social Interaction 45(3): 297-321.

Stommel W and Te Molder H (2015) Counseling online and over the phone: When preclosing questions fail as a closing device. Research on Language and Social Interaction 48(3): 281300.

Ten Have P (1978) Radio counselling (slightly revised quotes). In: 9th world congress of sociology, Uppsala, August. Available at: http://www.paultenhave.nl/RC-quotes.htm

Ten Have P (1989) The consultation as a genre. In: Torode B (ed.) Text and Talk as Social Practice. Dordrecht: Foris Publications, pp. 115-135.

Thell N and Jacobsson K (2016) 'And how old are you?': Age reference as an interpretative device in radio counselling. Journal of Aging Studies 39: 31-43.

Viklund E, Holmqvist R and Zetterqvist Nelson K (2010) Client-identified important events in psychotherapy: Interactional structures and practices. Psychotherapy Research 20(2): 151-164.

Weiste E (2015) Describing therapeutic projects across sequences: Balancing between supportive and disagreeing interventions. Journal of Pragmatics 80: 22-43.

Wills F and Sanders D (2013) Cognitive Behaviour Therapy: Foundations for Practice. London: SAGE.

Woods CJ, Drew P and Leydon GM (2015) Closing calls to a cancer helpline: Expressions of caller satisfaction. Patient Education and Counseling 98(8): 943-953.

Yan X (2008) TV talk show therapy as a distinct genre of discourse. Discourse Studies 10(4): 469-491.

Zetterqvist V, Andersson G and Kaldo V (2013) Leva Med Tinnitus [To live with Tinnitus]. Stockholm: Natur \& Kultur.

\section{Author biographies}

Nataliya Thell is a doctoral student at the School of Social Work, Faculty of Social Sciences at the Lund University. Her doctoral thesis is about a Swedish radio counselling programme, which is studied as a specific type of psychotherapeutic interaction. Her research interests involve application of conversation analysis to psychotherapy research, membership categorisation, interpretative resources in talk about troubles and discursive constructionism.

Anssi Peräkylä is a Professor in Sociology and the Vice-Director of the Centre of Excellence on Intersubjectivity in Interaction at the University of Helsinki. His research interests include social interaction in psychotherapy, medical consultations and everyday settings. His recent and ongoing research projects investigate emotional expression in social interaction and linkages between the process of social interaction and the physiological responses in the participants' bodies. 


\section{Appendix I}

The transcription symbols

RP Speaker identification: radio psychologist (RP), caller (C)

[ ] Starting point and end point of overlapping talk

(1.2) Silence measured in seconds

(.) Pause of less than 0.2 second

$=\quad$ No gap between two utterances

. Falling or final intonation

, Level or continuing intonation

? Rising intonation

word Stress or emphasis

wo:rd Prolongation of sound

WORD Loud voice

个word Raise in pitch or volume

\#word\# Creaky voice

wo- An abrupt cut-off

.h Inhalation

h. Exhalation

$>$ word $<\quad$ Compressed or rushed talk

$<$ word $>\quad$ Slowed or drawn out talk

$€$ word€ $\quad$ Smiley voice

heh/huh Laughter

wo(h)rd Laughter particle (aspiration) within a word

( ) Unclear segment of talk 